\title{
High incidence of surgical site infection may be related to suboptimal case selection of non-selective arterioembolisation during resuscitation of patients with pelvic fractures
}

\author{
Chih-Yang Lai \\ Chang Gung Memorial Hospital \\ I-Chuan Tseng \\ Chang Gung Memorial Hospital \\ Chun-Yi Su \\ Chang Gung Memorial Hospital \\ Yung-Heng Hsu \\ Chang Gung Memorial Hospital \\ Ying-Chao Chou \\ Chang Gung Memorial Hospital \\ Huan-Wu Chen \\ Chang Gung Memorial Hospital \\ Yi-Hsun Yu ( $\square$ alanyu1007@gmail.com ) \\ Chang Gung Memorial Hospital Linkou Branch https://orcid.org/0000-0002-3703-404X
}

\section{Research article}

Keywords: trauma of pelvis, infection, major trauma management, resuscitation and critical care

Posted Date: January 20th, 2020

DOI: https://doi.org/10.21203/rs.2.21247/v1

License: (c) (i) This work is licensed under a Creative Commons Attribution 4.0 International License. Read Full License

Version of Record: A version of this preprint was published at BMC Musculoskeletal Disorders on May 30th, 2020. See the published version at https://doi.org/10.1186/s12891-020-03372-5. 


\section{Abstract}

Background In most institutions, arterioembolisation (AE) remains a standard procedure to achieve haemostasis in the resuscitation of patients with pelvic fractures. However, the actual benefits from AE are controversial.

Methods We retrospectively reviewed data from patients with closed pelvic fractures between 2014 and 2017 in a single institute. The details of $\mathrm{AE}$ and clinical parameters were recorded and analysed to determine whether poor outcomes could be predicted.

Results During the study period, 545 patients with closed pelvic fractures were enrolled. Angiography was performed in 131 patients, and 129 patients underwent $A E$. The patients who underwent AE had higher injury severity score, more numbers of shock status on arrival, and higher incidence of unstable fracture patterns when compared to non-AE group. $A$ higher number of patients who underwent $A E$ required osteosynthesis and experienced surgical site infection (SSI) after osteosynthesis than those who did not receive AE. Nonselective bilateral internal iliac artery embolisation (nBIIAE) was the major approach for AE (74\%). Overall, 11 patients experienced SSI in the AE group, 9 of whom had received nBIIAE. The positive predictive value of contrast extravasation (CE) on computed tomography (CT) was $29.6 \%$, with a negative predictive value of $91.3 \%$. Mortality was higher in patients without CE on CT than patients with identifiable CE $(30.0 \%$ vs. $11.0 \%, p=0.03)$.

Conclusion Using the finding of CE on CT examination as a decision for AE is not a reliable indicator because of its low positive predictive value. Considering the high incidence of SSI following nBIIAE, candidates should be carefully selected for this procedure. Other haemostasis procedures such as preperitoneal pelvic packing might be considered for select cases, given the high mortality rate among patients without CE during image studies, relative to patients with identifiable CE.

\section{Background}

Pelvic fractures can often result in potentially lethal haemorrhage and hypotension [1, 2]. Thus, haemodynamically unstable patients with pelvic fractures are a major challenge for acute care and orthopedic surgeons, and the management of such patients is best performed by a multi-disciplinary team [3]. The appropriate acute management of haemodynamically unstable patients with pelvic fractures remains controversial. Arterioembolisation (AE) and preperitoneal pelvic packing (PPP) are the commonly used procedures in this setting, but there is no conclusive evidence on the superiority of either treatment $[2,4,5]$.

Some reports have described $A E$ as an effective procedure in the management of pelvic fracture-related retroperitoneal arterial haemorrhage $[6,7]$. Furthermore, $A E$ is a classical treatment and remains a standard haemostatic procedure in many institutions [7-9], including our institution, based on reports regarding its efficacy during the management of haemorrhage due to pelvic fractures $[8,10]$. However, $A E$ is associated with various complications, including inadequate haemostasis, gluteal muscle necrosis, and surgical site infection (SSI) $[11,12]$ In addition, selection of a patient for AE based only upon observing contrast extravasation (CE) on computed tomography (CT) examination is not reliable [13]. Nevertheless, additional information is needed to assess when AE provides optimal outcomes. The present study aimed to explore AE-related outcomes following resuscitation and assess the predictive value of CE on CT in patients with haemodynamically unstable closed pelvic fracture.

\section{Methods}

We retrospectively reviewed data, including clinical and imaging records, from all cases of pelvic fracture between January 2014 and December 2017 in the trauma registry of our institution. The study's retrospective protocol was 
approved by our institutional review board (IRB: 201802139B0). Patients were excluded if they had an isolated acetabular fracture, were dead upon arrival, were diagnosed with a pelvic fracture without imaging, or underwent $A E$ as a haemostatic procedure targeting non-pelvic regions. All patients with pelvic fractures were resuscitated and managed according to our established protocol, which was based on the Advanced Trauma Life Support guidelines.

At our institution, $A E$ is a standard procedure for pelvic fracture-related haemorrhage, and is performed when CE is detected during contrast-enhanced CT or for unstable patients who do not respond to resuscitation after the exclusion of other sources of haemorrhage. Briefly, angiography is first performed to evaluate the abdominal aorta, lumbar arteries, bilateral common iliac arteries, bilateral external iliac arteries, and bilateral internal iliac arteries. Selective or nonselective embolisation is then performed at the discretion of the interventional radiologist. After any AE the patients are admitted to the intensive care unit or the ward depending on their clinical requirements. Osteosynthesis for pelvic ring injuries is performed after the patient's clinical condition has stabilised.

The patients' demographic characteristics, injury severity score (ISS), fracture patterns, AE details, and AE-related complications were recorded. Complications were defined as adverse responses or unexpected conditions that were likely related to the AE procedure. We defined SSI as surgical wound complications after osteosynthesis with a positive bacterial culture. Information on impotence in men was self-reported at the 12-month follow-up visit.

Data were analysed using SPSS version 18.0 statistical software (SPSS Inc, Chicago, IL). Continuous variables were compared using the t-test and categorical variables were compared using the chi-squared test and Fisher's exact test. Predictive analyses were performed to determine whether the presence of CE on CT could be used to predict the AE outcomes.

\section{Results}

During the 48-month study period, we identified 545 patients with closed pelvic fractures who underwent resuscitation and treatment (Table 1). Traffic accident was the most common injury mechanism (70.2\%). Initial clinical assessments revealed that 112 patients $(20.6 \%)$ were in shock at the initial presentation and required resuscitation and blood transfusions. After resuscitation, 49 patients (43.8\%) were identified as responders whereas others were refractory to resuscitation. The CT assessments revealed that 390 patients $(71.5 \%)$ had partially stable or unstable ring pattern. Angiography was performed for 131 patients $(24 \%)$ who were unresponsiveness to resuscitation or presented with CE on CT examination. There were no complications during or immediately after the angiography procedure. AE was performed in 129/131 (98.5\%) of these patients following angiography (Table 2). 
Table 1

Demographic characteristics of patients with pelvic fracture during 2014-2017 at our institution

\begin{tabular}{|c|c|}
\hline Total number of patients & 545 \\
\hline Mean age (years) & $46.2 \pm 21.6$ \\
\hline $\begin{array}{l}\text { Sex, n (\%) } \\
\text { Male } \\
\text { Female }\end{array}$ & $\begin{array}{l}267(49.0 \%) \\
278(51.0 \%)\end{array}$ \\
\hline $\begin{array}{l}\text { Trauma mechanism, } \mathrm{n}(\%) \\
\text { Traffic accident } \\
\text { Falling from height } \\
\text { Other }\end{array}$ & $\begin{array}{l}383(70.2 \%) \\
145(26.6 \%) \\
17(3.2 \%)\end{array}$ \\
\hline Mean Injury Severity Score & $17.4 \pm 12.2$ \\
\hline Shock on arrival, n (\%) & $112(20.6 \%)$ \\
\hline $\begin{array}{l}\text { Fracture classification, } \mathrm{n}(\%) \dagger \\
\text { Stable ring } \\
\text { Partially stable ring } \\
\text { Unstable ring }\end{array}$ & $\begin{array}{l}277(50.8 \%) \\
113(20.7 \%) \\
155(28.5 \%)\end{array}$ \\
\hline $\begin{array}{l}\text { Imaging used to evaluate arterial bleeding, n (\%) } \\
\text { Computed tomography } \\
\text { Angiography }\end{array}$ & $\begin{array}{l}545(100 \%) \\
131(24.0 \%)\end{array}$ \\
\hline $\begin{array}{l}\text { Arterioembolisation, n (\%) } \\
\text { No } \\
\text { Yes }\end{array}$ & $\begin{array}{l}416(76.3 \%) \\
129(23.7 \%)\end{array}$ \\
\hline Osteosynthesis surgery for pelvic fracture, $\mathrm{n}(\%)$ & $211(38.7 \%)$ \\
\hline Mortality, n (\%) & $27(4.9 \%)$ \\
\hline
\end{tabular}


Table 2

Characteristics of the patients who underwent arterioembolisation

\begin{tabular}{|c|c|}
\hline Total patients (n) & 129 \\
\hline Mean available time (mins) & $63.8 \pm 44.7$ \\
\hline Shock on arrival, n (\%) & $90(69.7 \%)$ \\
\hline Non-responder to resuscitation, n (\%) & $47(36.4 \%)$ \\
\hline $\begin{array}{l}\text { Contrast extravasation, } \mathrm{n}(\%) \\
\text { On CT examination } \\
\text { On angiography examination }\end{array}$ & $\begin{array}{l}107(82.9 \%) \\
34(26.3 \%)\end{array}$ \\
\hline $\begin{array}{l}\text { Location of AE, n (\%) } \\
\text { BIIA } \\
\text { RIIA } \\
\text { LIIA. }\end{array}$ & $\begin{array}{l}97(74.0 \%) \\
17(12.9 \%) \\
15(11.8 \%)\end{array}$ \\
\hline $\begin{array}{l}\text { Material used for embolisation, } \mathrm{n}(\%) \\
\text { Gelfoam } \\
\text { Metal coils }\end{array}$ & $\begin{array}{l}118(91.4 \%) \\
11(8.6 \%)\end{array}$ \\
\hline Blood transfusion (ml) & $2388.1 \pm 2633.6$ \\
\hline Osteosynthesis surgery, n (\%) & $75(58.1 \%)$ \\
\hline $\begin{array}{l}\text { AE-related complications, n (\%) } \\
\text { Impotence in men } \\
\text { Surgical site infection }\end{array}$ & $\begin{array}{l}3 \\
11\end{array}$ \\
\hline $\begin{array}{l}\text { CT: computed tomography; AE: arteri } \\
\text { LIIA: left internal iliac artery. }\end{array}$ & teries, RIIA: right internal iliac artery, \\
\hline
\end{tabular}

The average available time for AE intervention, which was defined as the time from "order" to "door", was $63.8 \pm$ $44.7 \mathrm{~min}$. Ninety-seven patients (74.0\%) underwent non-selective bilateral internal iliac artery embolisation (nBIIAE), using gelfoam as the filling material. Only $11 / 129$ patients $(8.5 \%)$ underwent $A E$ using metal coils. Fourteen patients (10.9\%) experienced late complications following the AE intervention, including 3 men with impotence at the 12-months follow-up visit and 11 patients with SSIs after osteosynthesis. (Fig. 1). Nine of the 11 patients with SSIs (81.8\%) had undergone nBIIAE. The details of the patients with SSI are presented in Table 3. 
Table 3

Demographic details of patients with surgical site infections who underwent AE and osteosynthesis

\begin{tabular}{|c|c|c|c|c|c|c|c|c|c|c|}
\hline Case & Sex & $\begin{array}{l}\text { Age- } \\
\text { range }\end{array}$ & ISS & $\begin{array}{l}\text { Initial } \\
\text { shock }\end{array}$ & $\begin{array}{l}\text { Responder } \\
\text { to } \\
\text { resuscitation }\end{array}$ & $\begin{array}{l}\text { CE } \\
\text { on } \\
\text { CT }\end{array}$ & $\begin{array}{l}\text { CE on } \\
\text { Angiography }\end{array}$ & $\begin{array}{l}\text { Filling } \\
\text { material }\end{array}$ & $\begin{array}{l}\text { Surgical } \\
\text { approach }\end{array}$ & Bacteria \\
\hline 1 & male & $\begin{array}{l}20- \\
29\end{array}$ & 35 & yes & yes & yes & yes & Gelfoam & Posterior & $\begin{array}{l}\text { MDRAB, } \\
\text { E coli. } \\
\text { KP }\end{array}$ \\
\hline 2 & female & $\begin{array}{l}30- \\
39\end{array}$ & 32 & yes & no & no & no & Gelfoam & $\begin{array}{l}\text { Posterior } \\
+ \text { Anterior }\end{array}$ & MRSA \\
\hline 3 & male & $\begin{array}{l}50- \\
59\end{array}$ & 32 & yes & no & no & yes & Gelfoam & Posterior & OSSA \\
\hline 4 & male & $\begin{array}{l}20- \\
29\end{array}$ & 34 & yes & yes & yes & yes & Gelfoam & Posterior & MRSA \\
\hline 5 & female & $\begin{array}{l}60- \\
69\end{array}$ & 36 & yes & no & yes & no & Gelfoam & Anterior & MRSA \\
\hline 6 & male & $\begin{array}{l}20- \\
29\end{array}$ & 27 & yes & no & yes & no & Gelfoam & Anterior & MRSA \\
\hline 7 & female & $\begin{array}{l}60- \\
69\end{array}$ & 17 & yes & no & no & no & Gelfoam & $\begin{array}{l}\text { Posterior } \\
+ \text { Anterior }\end{array}$ & E coli \\
\hline 8 & female & $\begin{array}{l}40- \\
49\end{array}$ & 16 & yes & yes & yes & no & Gelfoam & Posterior & E coli \\
\hline 9 & female & $\begin{array}{l}40- \\
49\end{array}$ & 30 & no & yes & yes & no & Gelfoam & $\begin{array}{l}\text { Posterior } \\
+ \text { Anterior }\end{array}$ & MRSA \\
\hline 10 & female & $\begin{array}{l}18- \\
19\end{array}$ & 29 & yes & no & yes & no & Gelfoam & $\begin{array}{l}\text { Posterior } \\
+ \text { Anterior }\end{array}$ & MSSA \\
\hline 11 & male & $\begin{array}{l}40- \\
49\end{array}$ & 25 & no & yes & yes & yes & Gelfoam & Posterior & MSSA \\
\hline $\begin{array}{l}\text { ISS: i } \\
\text { Acine } \\
\text { Stapl }\end{array}$ & $\begin{array}{l}\text { sever } \\
\text { acter b } \\
\text { coccus }\end{array}$ & $\begin{array}{l}\text { core; } \\
\text { Ianni }\end{array}$ & $\mathrm{cc}$ & $\begin{array}{l}\text { st ext } \\
\text { scheri }\end{array}$ & $\begin{array}{l}\text { asation; CT: c } \\
\text { coli; KP: Klek }\end{array}$ & $\begin{array}{l}\text { iput } \\
\text { ella }\end{array}$ & $\begin{array}{l}\text { tomography; } \\
\text { eumonia; MRS } \\
\text { s aureus }\end{array}$ & $\begin{array}{l}\text { DRAB: mu } \\
\text { : methicilli }\end{array}$ & $\begin{array}{l}\text { drug-resis } \\
\text {-resistant }\end{array}$ & \\
\hline
\end{tabular}

Table 4 shows the comparisons between the patients who did and did not undergo AE. Patients who underwent AE had a higher ISS (26.1 vs. $14.5, p=0.01)$, a greater likelihood of being in shock upon arrival $(68.2 \%$ vs. $5.3 \%, p=0.001)$, a higher likelihood of having an unstable pelvic fracture pattern ( $55.9 \%$ vs. $19.9 \%, p=0.001)$, and a higher likelihood of undergoing osteosynthesis $(57.3 \%$ vs. $32.9 \%, p=0.001)$. The AE group also had significantly higher rates of impotence in men $(4.8 \%$ vs. $0.6 \%, p=0.036)$ and SSIs $(14.7 \%$ vs. $3.7 \%, p=0.006)$. 
Table 4

Demographic comparison between patients who underwent trans-arterial embolisation and those who did not

\begin{tabular}{|c|c|c|c|}
\hline & $\begin{array}{l}\text { Without TAE } \\
(n=416)\end{array}$ & $\begin{array}{l}\text { With TAE } \\
(n=129)\end{array}$ & $p$ value \\
\hline $\begin{array}{l}\text { Gender, n (\%) } \\
\text { Male } \\
\text { Female }\end{array}$ & $\begin{array}{l}205(49.2 \%) \\
211(50.8 \%)\end{array}$ & $\begin{array}{l}62(48.0 \%) \\
67(52.0 \%)\end{array}$ & 0.85 \\
\hline Age, years & $45.5 \pm 21.1$ & $48.3 \pm 22.5$ & 0.25 \\
\hline Shock on arrival, n (\%) & $22(5.3 \%)$ & $88(68.2 \%)$ & 0.001 \\
\hline ISST & $14.5 \pm 10.7$ & $26.1 \pm 12.0$ & 0.01 \\
\hline $\begin{array}{l}\text { Fracture classification, } \mathrm{n}(\%) \dagger \\
\text { Stable pelvic ring } \\
\text { Partially unstable pelvic ring } \\
\text { Completely unstable pelvic ring }\end{array}$ & $\begin{array}{l}245(58.9 \%) \\
88(21.2 \%) \\
83(19.9 \%)\end{array}$ & $\begin{array}{l}32(24.8 \%) \\
25(19.3 \%) \\
72(55.9 \%)\end{array}$ & 0.001 \\
\hline Surgery for pelvic fracture, $\mathrm{n}(\%)$ & $136(32.6 \%)$ & $75(58.1 \%)$ & 0.001 \\
\hline $\begin{array}{l}\text { Complications, } n(\%) \\
\text { Impotence (male) } \\
\text { Surgical site infection }\end{array}$ & $\begin{array}{l}1(0.6 \%) \\
5(3.7 \%)\end{array}$ & $\begin{array}{l}3(4.9 \%) \\
11(14.7 \%)\end{array}$ & $\begin{array}{l}0.036 \\
0.006\end{array}$ \\
\hline Mortality, n (\%) & $5(1.2 \%)$ & $18(13.7 \%)$ & 0.001 \\
\hline \multicolumn{4}{|c|}{ †The classification of the pelvic fracture was based on AO/OTA classification (2018 revision } \\
\hline ISS: injury severity score. & & & \\
\hline
\end{tabular}

We noted that not all patients who underwent $A E$ presented with identifiable evidence of arterial bleeding at the time of imaging $(109 / 129,84.5 \%)$. Therefore, we compared the characteristics of patients with and without identifiable CE on CT to determine whether AE was useful (Table 5). No significant differences were detected in initial shock status, responding to resuscitation, age, sex, ISS, the available time for $A E$, fracture classification, the volume of blood transfusion and the rate of repeat AE between the 2 groups. However, patients without identifiable CE during CT and angiography had a significantly higher 1 -week in-hospital mortality rate than patients with identifiable CE (30.0\% vs. $11.0 \%, p=0.03$ ). 
Table 5

Comparison in patients who underwent $\mathrm{AE}$ with and without evidence of contrast extravasation on computed tomography assessment

\begin{tabular}{|c|c|c|c|}
\hline & $\begin{array}{l}\text { With evidence of CE } \\
(n=111)\end{array}$ & $\begin{array}{l}\text { Without evidence of CE } \\
(n=20)\end{array}$ & p value \\
\hline $\begin{array}{l}\text { Gender, } \mathrm{n}(\%) \\
\text { Male } \\
\text { Female }\end{array}$ & $\begin{array}{l}55(49.5 \%) \\
56(50.5 \%)\end{array}$ & $\begin{array}{l}8(40.0 \%) \\
12(60.0 \%)\end{array}$ & 0.47 \\
\hline Age & $48.1 \pm 22.9$ & $50.1 \pm 20.7$ & 0.33 \\
\hline ISS & $26.2 \pm 12.4$ & $28.4 \pm 9.8$ & 0.13 \\
\hline Available time for angiography (min) & $64.0 \pm 46.9$ & $62.9 \pm 30.7$ & 0.66 \\
\hline Repeat AE, n (\%) & $3(2.7 \%)$ & $2(10.0 \%)$ & 0.17 \\
\hline $\begin{array}{l}\text { Fracture classification, } \mathrm{n}(\%) \\
\text { stable ring } \\
\text { partially stable ring } \\
\text { unstable ring }\end{array}$ & $\begin{array}{l}32(28.8 \%) \\
32(28.8 \%) \\
47(42.3 \%)\end{array}$ & $\begin{array}{l}6(30.0 \%) \\
4(20.0 \%) \\
10(50.0 \%)\end{array}$ & 0.69 \\
\hline Osteosynthesis surgery for pelvic fracture, $\mathrm{n}(\%)$ & $62(55.8 \%)$ & $13(65.0 \%)$ & 0.62 \\
\hline AE of BIIA, $n(\%)$ & $82(73.8 \%)$ & $15(75.0 \%)$ & 0.59 \\
\hline Mortality, n (\%) & $12(10.8 \%)$ & $6(30.0 \%)$ & 0.04 \\
\hline
\end{tabular}

One of the indication for $A E$ in our institution was the presence of CE on CT. Therefore, we examined the relationship between identifiable bleeding during CT and angiography to detect the effectiveness of CT in assessing arterial bleeding in patients with unstable pelvic fractures. We used the angiography results as a standard baseline to examine the predictive value of CT examination. CT examination upon ED arrival was performed in all 131 patients who underwent angiography, which revealed retroperitoneal bleeding in 108/131 patients (82.4\%). However, CE was only identified in $34 / 131$ patients $(26.3 \%)$ during the angiography. Predictive analysis revealed that CE during CT has a sensitivity of $94.1 \%$, specificity of $21.6 \%$, a positive predictive value (PPV) of $29.6 \%$, and a negative predictive value (NPV) of $91.3 \%$.

\section{Discussion}

Pelvic fractures may be accompanied by haemorrhage, which can lead to haemodynamic instability and death. At our institution, $A E$ intervention is a standard procedure in this setting and is associated with good bleeding control outcomes $[8,10]$. Since delayed angiography in these patients is associated with poor outcomes $[8,14,15]$, we believe that prompt availability of $A E$ (60 minutes from order to door) and good treatment efficacy (based on a low rate of repeat $A E$ ) explain the low mortality rate of pelvic fracture-related haemorrhage in our institution. However, owing to technological improvements and increased availability more vascular injuries are found during CT examinations. Nonetheless, recent studies have indicated that imaging-based evidence of CE does not necessarily indicate a need for AE to control bleeding $[4,16-18]$, suggesting that a rapid $A E$ intervention following pelvic fracture might not be an optimal step during the chaotic resuscitation process. In the present study, $82.4 \%$ of patients in the AE group exhibited signs of arterial bleeding during CT examination, while only $26 \%$ of patients exhibited signs of CE on angiography yielding a positive predictive value of only $29.6 \%$ for using CT to detect arterial injury in patients with pelvic fractures, which is similar to the results from previous studies $[19,20]$. Although previous publications have proposed that CT evidence of CE is a major 
indication for $A E[7,21]$, our results have shown otherwise. We believe that angiography examination or $A E$ should be performed based on a combination of clinical findings such as nonresponder status to resuscitation or ongoing fall in haemoglobin concentration without any evidence of bleeding from other sources and negative arterial blush sign on CT.

Although non-selective embolisation for haemodynamically unstable patients with pelvic fractures is considered a haemostatic procedure [7, 22], in case of vasospasm or rich collateral arterial network within the pelvis, current studies have focused on selective or super-selective embolisation to decrease the negative impacts of non-selective embolization [23, 24]. Since the AE intervention might be accompanied by a high complication rate after these patients undergo osteosynthesis to treat their unstable pelvis, we also assessed the outcomes of different AE approaches. The present study revealed that $74 \%$ of patients underwent $\mathrm{nBIIAE}$ if they required to undergo an $\mathrm{AE}$ intervention. Nine of the 11 patients who experienced SSIs after AE had undergone an $\mathrm{nBIIAE}$ intervention. Although injuries to the soft tissue surrounding pelvic girdle, such as Morel-Lavallee lesion, following high energy trauma might contribute to SSI, the negative impact from nBIIAE as a leading cause for SSI cannot be ignored.

Contrast enhanced CT scans to detect arterial bleeding within the pelvis have become routine in many institutions [25], including our institute. However, we found that the ability of CT to detect arterial bleeding had a low PPV and a high NPV compared to the gold standard of angiography. Hence, a positive CE on CT scan might not be an appropriate indication to perform $\mathrm{AE}$ as a haemostasis procedure. We also observed that patients with no signs of CE on imaging studies had a significantly higher mortality rate after $\mathrm{AE}$, compared to those in whom CE was detected on CT scan $(30.0 \%$ vs. $11.0 \%$, $p=0.03$ ). There were no significant differences in age, sex, ISS, the available time for $A E$, fracture classification, the volume of blood transfusion, and the rate of repeat AE between the 2 groups. We speculate that patients who do not show any CE on CT imaging might be experiencing shock due to sources other than arterial injury, such as cancellous fracture surface bleeding or venous plexus bleeding. Thus, in these patients AE provides limited benefit while delaying the resuscitation procedure. Therefore, $A E$ should not be a routine haemostasis procedure for haemodynamically unstable patients with unstable pelvic fractures, and other haemostasis procedures, such as PPP, should also be considered as an alternative during the resuscitation process in these patients.

Although we made every effort to reduce analysis bias, the present study has several limitations. First, the retrospective design is associated with risks of bias, and we observed that cases that required AE were naturally more severe and had higher ISS scores than those which did not. Thus, the higher complication rate in the AE group might reflect the severity of the patient's injuries, and strict selection criteria may be needed for the AE procedure to avoid further complications that are difficult to manage. Second, although our centre uses an established protocol to identify patients who should undergo angiography, the choice of selective or non-selective embolisation was based on the radiologist's discretion. The interventional radiologists commonly noted that non-selective embolisation was performed "to facilitate haemostasis", even when no arterial bleeding was identified during angiography. Third, AE has been performed at our centre during the last two decades as part of a fixed protocol for haemodynamically unstable patients with pelvic fractures, and it may be difficult to encourage experienced emergency traumatologists to include PPP as another approach in our resuscitation protocol.

\section{Conclusions}

In conclusion, we believe that angioembolisation is an effective, time-saving, and readily available procedure for pelvic fracture-related arterial haemorrhage. However, the procedure might be associated with higher rate of SSI, especially among patients who underwent non-selective non-selective embolisations. In addition, patients without identifiable CE during angiography had a relatively high mortality rate, despite AE. Thus, it may be appropriate to perform more selective or super-selective embolisation procedure in carefully selected patients, and to consider PPP as an additional approach to haemostasis in the resuscitation protocol when there are no imaging-based signs of arterial bleeding.

Page 9/13 


\section{Abbreviations}

AE

Arterioembolisation; CE:Contrast extravasation; CT:Computed tomography; ED:Emergency department; ISS:injury severity score; NPV:Negative predictive value; nBIIAE:Nonselective bilateral internal iliac artery embolization; SSI:Surgical site infection; PPP:Preperitoneal pelvic packing; PPV:positive predictive value; SSI:Surgical site infection.

\section{Declarations}

\section{Acknowledgements}

Not applicable.

\section{Funding}

Not applicable.

\section{Availability of data and materials}

All data generated or analysed during this study are included in this published article.

\section{Authors' contributions}

Conceptualisation: I.-C.T., C.-Y.S. and Y.-H.Y.; Investigation: C.-Y.L. and Y.-H.Y.; Writing: C.-Y.L. and Y.-H.Y.; Review and Editing: Y.-H.H. and Y.-C.C. and W.-L.Y.; Supervision: Y.-H.Y. All authors have read and approved the final version of the manuscript.

\section{Ethics approval and consent to participate}

This study was approved by the Institutional Review Board (IRB) of Chang Gung Medical Foundation according to Good Clinical Practice and the applicable laws and regulations (IRB number: 201802139B0).

\section{Consent for publication}

Not applicable

Competing interests The authors declare that they have no competing interests

Data availability All data supporting our findings are contained within the manuscript.

Patient Consent for publication Not applicable.

\section{References}

1.

Hou Z, Smith WR, Strohecker KA, et al. Hemodynamically unstable pelvic fracture management by advanced trauma life support guidelines results in high mortality. Orthopedics. 2012;35:319-24.

2. 
Godinho M, Garcia Dde F, Parreira JG, et al. Management of hemorrhage in patients with pelvic fracture and hemodynamically unstable. Rev Col Bras Cir. 2012;39:238-42.

3.

Stein DM, O'Toole R, Scalea TM. Multidisciplinary approach for patients with pelvic fractures and hemodynamic instability. Scand J Surg. 2007;96(4):272-80.

4.

Cullinane DC, Schiller HJ, Zielinski MD, et al. Eastern Association for the Surgery of Trauma practice management guidelines for hemorrhage in pelvic fracture-update and systematic review. J Trauma. 2011;71:1850-68.

5 .

Katsura M, Yamazaki S, Fukuma S, et al. Comparison between laparotomy first versus angiographic embolization first in patients with pelvic fracture and hemoperitoneum: a nationwide observational study from the Japan Trauma Data Bank. Scand J Trauma Resusc Emerg Med. 2013;21:82.

6.

Comai A, Zatelli M, Haglmuller T, et al. The Role of Transcatheter Arterial Embolization in Traumatic Pelvic Hemorrhage: Not Only Pelvic Fracture. Cureus. 2016;8:e722.

7.

Fu CY, Chan SY, Wang SY, et al. The effect of angioembolization for life-threatening retroperitoneal hemorrhage in patients with pelvic fracture. Am J Emerg Med. 2019;37:603-7.

8.

Hauschild O, Aghayev E, von Heyden J, et al. Angioembolization for pelvic hemorrhage control: results from the German pelvic injury register. J Trauma Acute Care Surg. 2012;73:679-84.

9.

Morozumi J, Homma H, Ohta S, et al. Impact of mobile angiography in the emergency department for controlling pelvic fracture hemorrhage with hemodynamic instability. J Trauma. 2010;68:90-5.

10.

Kuo LW, Yang SJ, Fu CY, et al. Relative hypotension increases the probability of the need for angioembolisation in pelvic fracture patients without contrast extravasation on computed tomography scan. Injury. 2016;47:37-42.

11.

Manson TT, Perdue PW, Pollak AN, et al. Embolization of pelvic arterial injury is a risk factor for deep infection after acetabular fracture surgery. J Orthop Trauma. 2013;27:11-5.

12.

Lindvall E, Davis J, Martirosian A, et al. Bilateral Internal Iliac Artery Embolization Results in an Unacceptably High Rate of Complications in Patients Requiring Pelvic/Acetabular Surgery. J Orthop Trauma. 2018;32:445-51.

13.

Ramin S, Hermida M, Millet I, et al. Limits of intravascular contrast extravasation on computed tomography scan to define the need for pelvic angioembolization in pelvic blunt trauma: a specific assessment on the risk of false positives. J Trauma Acute Care Surg. 2018;85:527-35.

14.

Tesoriero RB, Bruns BR, Narayan M, et al. Angiographic embolization for hemorrhage following pelvic fracture: Is it "time" for a paradigm shift? J Trauma Acute Care Surg. 2017;82:18-26.

15.

Matsushima K, Piccinini A, Schellenberg M, et al. Effect of door-to-angioembolization time on mortality in pelvic fracture: Every hour of delay counts. J Trauma Acute Care Surg. 2017;84:685-92.

16.

Brasel KJ, Pham K, Yang H, et al. Significance of contrast extravasation in patients with pelvic fracture. J Trauma. 2007;62(5):1149-52.

Page $11 / 13$ 
17.

Lai YC, Wu CH, Chen HW, et al. Predictors of active arterial hemorrhage on angiography in pelvic fracture patients. Jpn J Radiol. 2018;36:223-30.

18.

Verbeek DO, Zijlstra IA, van der Leij C, et al. Management of pelvic ring fracture patients with a pelvic "blush" on early computed tomography. J Trauma Acute Care Surg. 2014;76:374-9.

19.

Ramin S, Hermida M, Millet I, et al. Limits of intravascular contrast extravasation on computed tomography scan to define the need for pelvic angioembolization in pelvic blunt trauma: a specific assessment on the risk of false positives. J Trauma Acute Care Surg. 2018;85:527-35.

20.

Juern JS, Milia D, Codner P, et al. Clinical significance of computed tomography contrast extravasation in blunt trauma patients with a pelvic fracture. J Trauma Acute Care Surg. 2017;82:138-40.

21.

Barentsz MW, Vonken EP, van Herwaarden JA, et al. Clinical outcome of intra-arterial embolization for treatment of patients with pelvic trauma. Radiol Res Pract. 2011;2011:935484.

22.

Scemama U, Dabadie A, Varoquaux A, et al. Pelvic trauma and vascular emergencies. Diagn Interv Imaging. 2015;96:717-29.

23.

Auerbach AD, Rehman S, Kleiner MT. Selective transcatheter arterial embolization of the internal iliac artery does not cause gluteal necrosis in pelvic trauma patients. J Orthop Trauma. 2012;26:290-5.

24.

Hymel A, Asturias S, Zhao F, et al. Selective versus nonselective embolization versus no embolization in pelvic trauma: A multicenter retrospective cohort study. J Trauma Acute Care Surg. 2017;83:361-7.

25.

Joshi AR, Komwad AL, Joshi SA. Role of CT in Abdominal and Pelvic Trauma. Curr Radiol Rep. 2014;2:67.

\section{Figures}




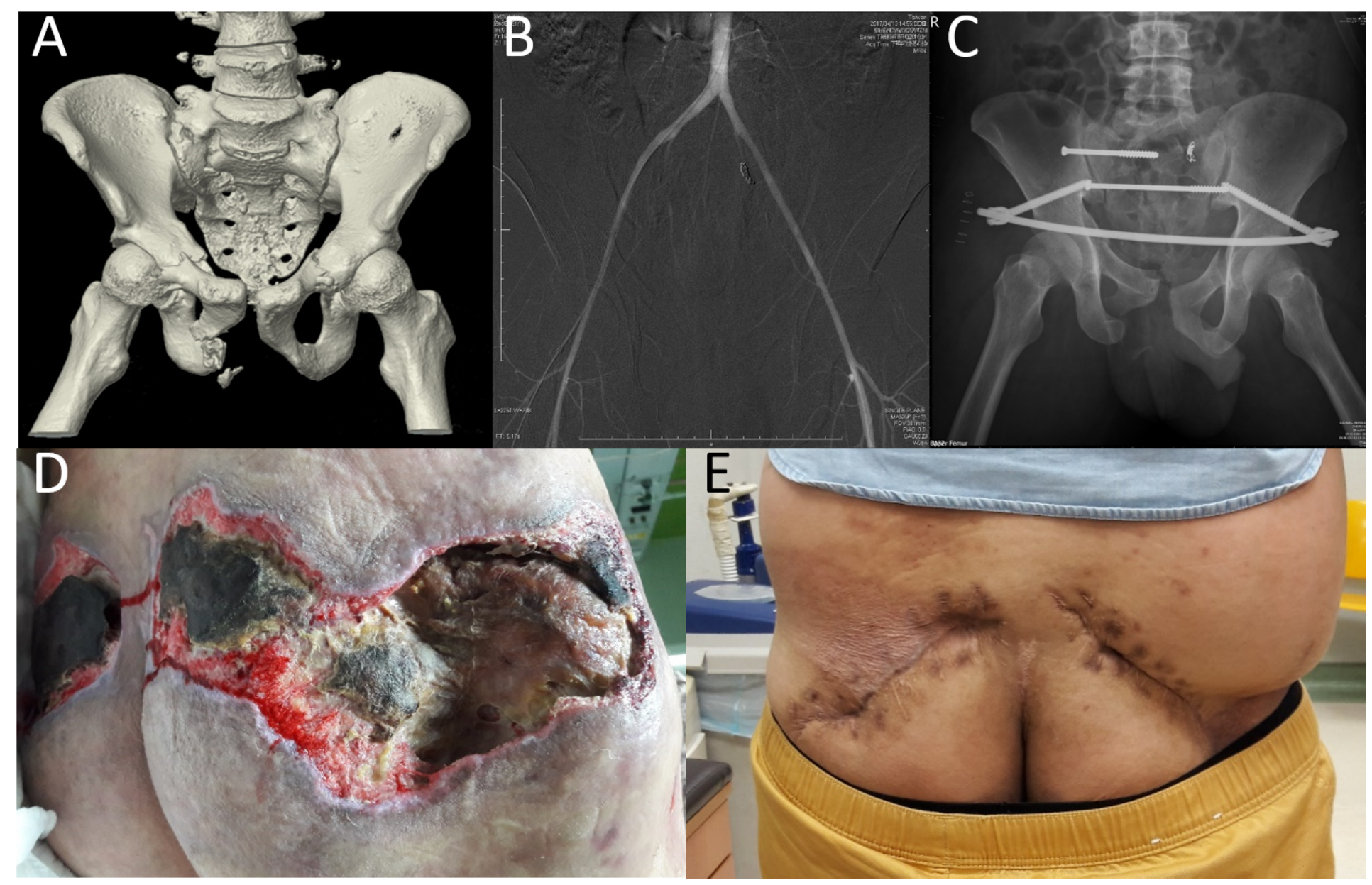

Figure 1

A case with surgical site infection due to trans-arterial embolisation after osteosynthesis surgery for pelvic ring injury. (A) Computed tomography revealed an AO/OTA B3.1 pelvic ring injury. (B) Bilateral internal iliac artery trans-arterial embolisation was performed using gelfoam (right side) and metal coil (left side). (C) Radiographic findings after osteosynthesis surgery. (D) Significant bilateral gluteus maximus necrosis was observed 1 month after trans-arterial embolisation. (E) Final appearance after treatment for the soft-tissue defect. 